\title{
Organic honey from Trás-Os-Montes region (Portugal): Chemical, palynological, microbiological and bioactive compounds characterization
}

\author{
Leticia M. Estevinho $^{\mathrm{a}, *}$, Xesús Feás ${ }^{\mathrm{b}}$, Julio A. Seijas ${ }^{\mathrm{b}}$, M. Pilar Vázquez-Tato ${ }^{\mathrm{b}}$ \\ ${ }^{a}$ CIMO-Mountain Research Center, Agricultural College of Bragança, Polytechnic Institute of Bragança, Campus Santa Apolónia, E 5301-855 Bragança, Portugal

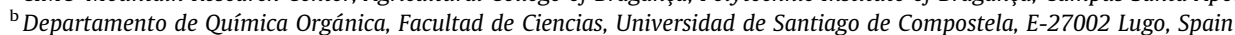

\section{A R T I C L E I N F O}

\section{Article history:}

Received 9 August 2011

Accepted 5 October 2011

Available online 13 October 2011

\section{Keywords:}

Honey

Organic

Physico-chemical analysis

Bioactive compounds

Microbiological analysis

Erica sp.

\begin{abstract}
A B S T R A C T
At the present time, the quality, integrity, sanitation and nutritional value of honeys receive attention on an international level due to the increasing content of chemicals in the aforementioned matrix. This work was conducted to evaluate the quality of 75 organic honey samples from the Trás-Os-Montes region (Portugal). Mean values obtained for physico-chemical parameters were: $\mathrm{pH} 3.7 ; 15.6 \%$ moisture; $0.26 \mathrm{mS} / \mathrm{cm}$ electrical conductivity; $0.25 \%$ ash; $1.1 \mathrm{mg} / \mathrm{kg}$ HMF; 15.3 Gothe diastase activity; $40.3 \mathrm{meq} / \mathrm{kg}$ free acidity; $67.8 \%$ invert sugars and $2.7 \%$ apparent sucrose. All honey samples can be classified as monofloral Erica sp., as showed by pollen features. The amounts of phenols and flavonoids in the samples were also determined. In respect to sanitary quality (fecal coliforms) and safety (sulfite-reducing clostridia and Salmonella), all organic honey samples were negative. Furthermore, yeast and molds were detected in low counts, with mean values obtained of $5.5 \mathrm{cfu} / \mathrm{g}$ and the value of total aerobic mesophiles obtained from honeys was established in $1.3 \times 10^{2} \mathrm{cfu} / \mathrm{g} \pm 7.5 \times 10^{1} \mathrm{cfu} / \mathrm{g}$. The levels of flavonoids had a stronger impact on both mesophiles $(p=0.0004)$ and molds $(p=0.0138)$ than the sucrose concentration $(p=0.001$ and 0.0278 ; respectively). The results reported in this study should be introduced in the organic honey label, and may help beekeepers, the industry, researchers and consumers better understand honey properties. (c) 2011 Elsevier Ltd. All rights reserved.
\end{abstract}

\section{Introduction}

Apiculture is a valuable and exceptional example of an environmentally sustainable production model, crucial for biodiversity and for agriculture, and characterized by a confluence of: (i) Economic interests (production of honey and by-products of the hive, which provide returns); (ii) Social aspects (fixation of the rural population in territories where hardly any other economic activities) and (iii) Environment maintenance (not only environmentally friendly but also as a service to society through the pollination of cultivated and wild fields) (Allsopp et al., 2008).

Today, having survived all kinds of climatic changes, bees are threatened, and therefore global food security, if pollinators, mainly honeybee, decline or disappear (Cuthbertson and Brown, 2009). The cause of the problem is still unknown, which is why it is being described as Colony Collapse Disorder (CCD) and researchers suspect this may be due to a combination of various diseases, environmental pollution, and farming practices, mainly due to an abusive use of increasingly toxic phytosanitary products and large monoculture cropping (Oldroyd, 2007).

When analyzing and studying the therapeutic properties of honeys, modern science has made it possible to specify their medical significance for healing wounds and burns (Molan, 2001),

\footnotetext{
* Corresponding author. Tel.: +351 273 303342; fax: +351 273325405

E-mail address: Leticia@ipb.pt (L.M. Estevinho).
}

oncology care (Bardy et al., 2008), as well as its antioxidant and antimicrobial factors (Gomes et al., 2010; Akbulut et al., 2009; Theunissen et al., 2001). It is clear that honeys to be used for therapeutic purposes should be harvested in areas with no contamination sources (Feás and Estevinho, 2011).

In any case, concerns about traces of numerous toxic substances have prompted some demand for honey that is certified as organic (Rial-Otero et al., 2007). Organic honey production is an ecologically based system, which encourages the use of good agricultural practices to maintain the agricultural ecosystem balance and diversity, promoting the sustainable use of natural resources, environmental quality, animal welfare and human health (EU, 2007). Research results indicate that the botanic origin of honey, different beehive types, and the material beehives are made of, have an influence on the development of bee diseases and the quality of honey (Tucak et al., 2004).

The progressive increase in the market of imported honey, with lower prices and inferior quality, has recently led to a growing need to asses authenticity of local, specially monofloral honeys, using a full quality control based on a physicochemical, microbiological and geographical description (Andrade et al., 1999; Azeredo et al., 2003; Pires et al., 2009; Feás et al., 2010a,b; Du Toit et al., 1995). However the full characterization of honey is not abundant and there is a lack of information about the characteristics of honey certified as organic (Magkos et al., 2003). 

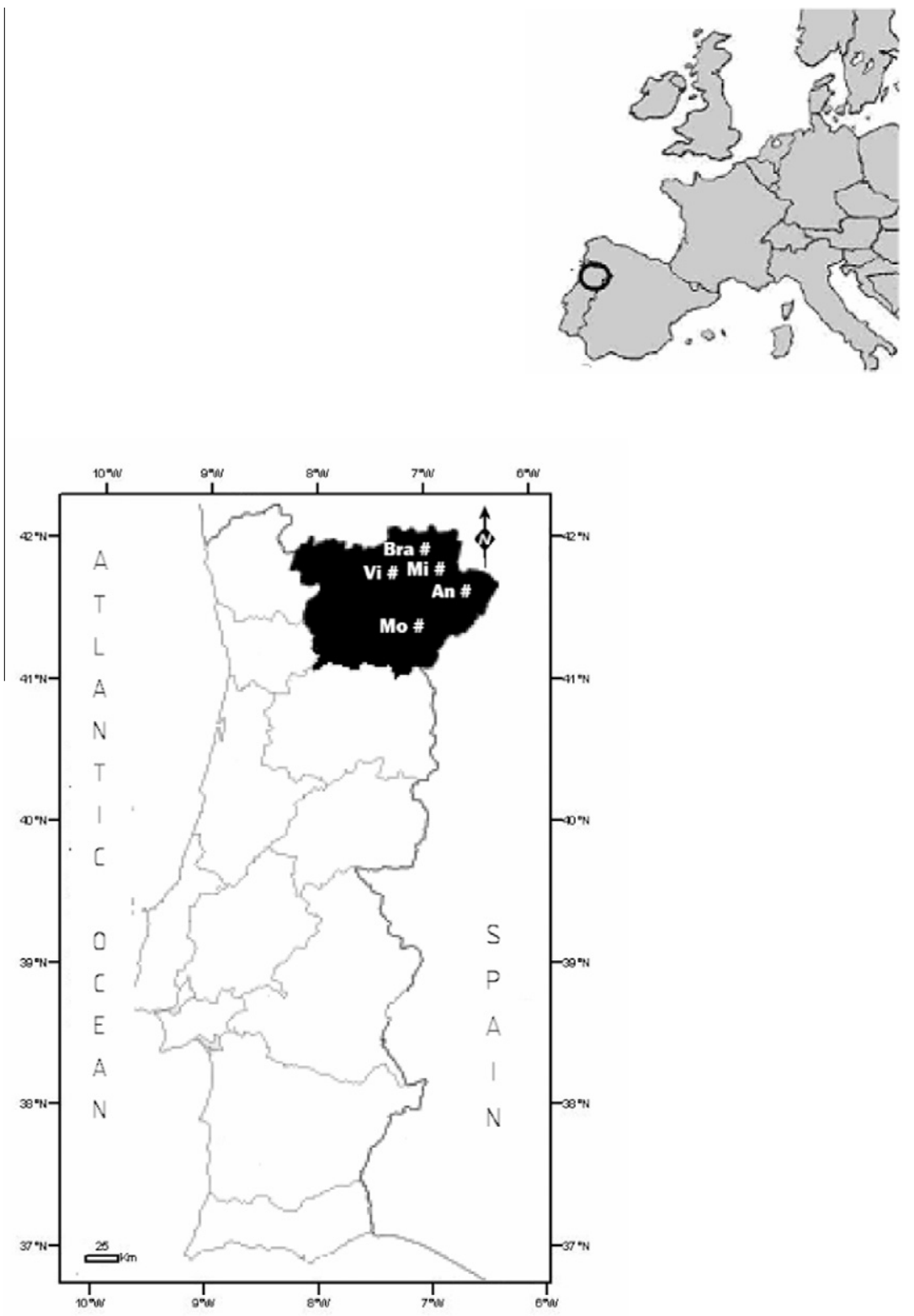

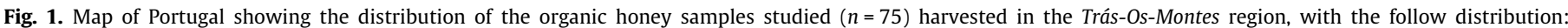
Mogadouro (Mo, $n=15$ ); Milhão (Mi, $n=15$ ); Angueira (An, $n=15$ ); Bragança (Bra, $n=15$ ) and Vinhais $(\mathrm{Vi}, n=15$ ).

The organic strict guidelines mean that is almost impossible for any beekeeper to be certified as organic. However Portugal possesses a very diverse natural heritage thanks to its geographical location and geophysical conditions (Araújo, 1999). Moreover, presently in the Portuguese continental territory there are 29 Special Protected Areas and 60 Sites of Community Importance which deals with the conservation of natural habitats and wild fauna and flora that are considered to be threatened in the European Union (EU, 1992).

Currently, Portugal has the highest number of honeys bearing the European Protected Designation of Origin logo, a total of nine, which are produced, processed and prepared in a given geographical area using certified know-how (EU, 2006). The detailed characterization of the different honey types existent in Portugal is important, once it will allow the establishment of technical specifications, avoiding occurrence of adulterations.

The present study aimed to characterize, for the first time, organic honeys harvested in Portugal, and more specifically in the Trás-Os-Montes region, in respect to: (i) floral nectar origin, (ii) physico-chemical parameters, (iii) bioactive compounds and (iv) microbial safety.

\section{Materials and methods}

\subsection{Honey sampling}

Seventy-five $(n=75)$ organic honey samples, from Apis mellifera, were supplied by beekeepers from different organic apiaries in the Trás-Os-Montes region. Fig. 1 shows the geographical origin of the organic honey samples studied. The samples were harvested from 5 localities: Mogadouro (Mo, $n=15$ ); Milhão (Mi, $n=15$ ); Angueira (An, $n=15)$; Bragança (Bra, $n=15$ ) and Vinhais (Vi, $n=15$ ).

\subsection{Botanical origin identification}

Even though the beekeepers themselves, according to the best of their knowledge and the location of hives, declared organic honey as monofloral heather (Erica sp.) honey, all the samples were subjected to pollen analysis as per the acetolysis method (Erdtman) reported previously in detail (Feás et al., 2010b). The examina- 
tion of the pollen slides was carried out with a Leitz Diaplan microscope (Leitz Messtechnik GmbH, Wetzlar, Germany) at $400 \times$ and $1000 \times$ in order to make a sound identification of the pollen types. A minimum of 1000 pollen grains was counted per sample. In order to recognize the pollen types, we used the reference collection from the CIMO-Mountain Research Center (Agricultural College of Bragança, Polytechnic Institute of Bragança) and different pollen morphology guides. The following terms were used for pollen frequency classes: predominant pollen ( $P$, more than $45 \%$ of pollen grains counted), secondary pollen (S, 16-45\%), important minor pollen (IM, 3-15\%) and minor pollen (M, 1-3\%) (Louveaux et al., 1970).

\subsection{Chemical analysis}

Analyses of the physico-chemical properties of organic honey samples were performed in accordance with the Official Methods of Analysis of Association of Official Analytical Chemists and The Harmonized Methods of the European Honey Commission, reported previously in detail (Feás et al., 2010b) The evaluated parameters were: water content (\%), ash (\%), electrical conductivity $(\mathrm{mS} / \mathrm{cm})$, hydroxymethylfurfural content (HMF) ( $\mathrm{mg} / \mathrm{kg}$ ), free acidity (meq $/ \mathrm{kg}$ ), diastase activity (Gothe degrees), reducing sugars (\%), apparent sucrose (\%) and $\mathrm{pH}$. Three replicate analyses were made from each sample to obtain the reported data.

\subsection{Bioactive compounds}

\subsubsection{Estimation of total phenolic contents}

The total phenolic content in honey was estimated according to the Folin-Ciocalteau method described by Moreira et al. (2008). Briefly, the reaction of $500 \mu \mathrm{L}$ honey in $\mathrm{MeOH}$, mixed with $500 \mu \mathrm{L}$ of the Folin-Ciocalteau reagent and $500 \mu \mathrm{L}$ of $\mathrm{Na}_{2} \mathrm{CO}_{3}(10 \% \mathrm{w} / \mathrm{v})$ was kept in the dark at room temperature for $1 \mathrm{~h}$, after which the absorbance was read at $700 \mathrm{~nm}$. Gallic acid (GA) standard solutions (0.01$0.08 \mathrm{mM})$ were used for constructing the calibration curve $(Y=2.3725 X+0.0021$; $\left.R^{2}=0.9998\right)$. Total phenols content were expressed as $\mathrm{mg}$ of GA equivalents $/ \mathrm{kg}$ of honey (GAEs)

\subsubsection{Estimation of total flavonoids contents}

For flavonoid contents determination, the sample $(250 \mu \mathrm{L})$ was mixed with $1.25 \mathrm{~mL}$ of distilled water and $75 \mu \mathrm{L}$ of a $5 \% \mathrm{NaNO}_{2}$ solution. After $5 \mathrm{~min}, 150 \mu \mathrm{L}$ of a $10 \% \mathrm{AlCl}_{3}-\mathrm{H}_{2} \mathrm{O}$ solution was added. After $6 \mathrm{~min}, 500 \mu \mathrm{L}$ of $1 \mathrm{M} \mathrm{NaOH}$ and $275 \mu \mathrm{L}$ of distilled water were added to the mixture. The solution was mixed well and the intensity of pink color was measured at $510 \mathrm{~nm}$. (+)-Catechin was used to calculate the standard curve $\left(0.022-0.34 \mathrm{mM} ; \quad Y=0.9990 X-0.0497 ; R^{2}=\right.$ $0.9961)$ and the results were expressed as $\mathrm{mg}$ of (+)-catechin equivalents $/ \mathrm{kg}$ of honey (CEs).

\subsection{Microbiological analysis}

Ten grams of each organic honey sample was weighed aseptically and homogenized with $90 \mathrm{~mL}$ of sterile peptone water $\left(10^{-1}\right.$ dilution $)$ in a stomacher bag. Subsequent decimal dilutions were prepared using the same diluent. Aerobic mesophilic bacteria were counted onto standard plate count agar (PCA) and incubated at $30{ }^{\circ} \mathrm{C}$ for $48 \mathrm{~h}$. Mold and yeast counts followed the protocol of ISO 21527-2:2008. Microbial counts were expressed as colony-forming units per gram of honey (cfu/g). For sulphite-reducing clostridia counting, aliquots of 10,5,1 and $0.1 \mathrm{~mL}$ of the initial suspension were added to an empty tube, thermally treated at $80^{\circ} \mathrm{C}$ for $5 \mathrm{~min}$ and covered with SPS (sulphite-polymixin-sulfadiazine) agar media, tubes were incubated at $37^{\circ} \mathrm{C}$ for 5 days. Then fecal coliforms and Salmonella detection were analyzed. Fecal coliforms were enumerated by the Most Probable Number technique defined in the protocol. Salmonella detection followed the protocol of ISO 6579:2002(E). All microbial tests were performed in triplicate.

\section{Results and discussion}

\subsection{Pollen analysis}

For honey, one of the fundamental aspects of quality that affects its commercial value is its botanical and geographical declaration of origin. The results of honey's pollen profile analysis allows us to determine its floral origin and to confirm the identity of the honey source indicated by the beekeepers. The identified pollen grains and their frequency on the analyzed organic honeys are presented in Table 1. Results from the quantitative pollen analysis showed that the samples analyzed always had Erica sp. as the predominant pollen (at least 45\%) and can be classified as monofloral Erica sp. Monofloral status generally refers to the presence of a single pollen type in quantities greater than $45 \%$ of the total pollen content in the spectrum. For honey samples having under-represented pollen grains, (i.e., Thymus, Rosmarinus, Citrus, and Arbutus), botanical classification must be achieved with a pollen frequency percentage of only $10-20 \%$. However, for honey types characterized by overrepresented pollen grains, (i.e., Castanea, Cynoglossum and Myosotis) botanical origin may be achieved with a pollen frequency percentage of $70-90 \%$.

Table 1

Frequency classes, presence, range and media of the pollen types in the honeys.

\begin{tabular}{|c|c|c|c|c|c|c|c|}
\hline \multirow[t]{2}{*}{ Locality } & & \multicolumn{6}{|l|}{ Pollen type } \\
\hline & & Erica sp. & Lavandula sp. & Castanea sp. & Cistus sp. & Echium sp. & Rubus sp. \\
\hline \multirow[t]{4}{*}{ Mogadouro $(n=15)$} & Presence $^{\mathrm{a}}$ & $15 \mathrm{P}$ & $8 \mathrm{IM}, 7 \mathrm{M}$ & $2 \mathrm{~S}, 13 \mathrm{IM}$ & 4 IM, $11 \mathrm{M}$ & 13 S, 2 IM & $15 \mathrm{M}$ \\
\hline & $\%{ }^{\mathrm{b}}$ & 100 & $53.5,46.7$ & $13.3,86.7$ & $26.7,73.3$ & $86.7,13.3$ & 100 \\
\hline & Mean \pm SD & $59.8 \pm 0.8$ & $2.9 \pm 0.2$ & $15.3 \pm 0.5$ & $2.9 \pm 0.2$ & $16.5 \pm 0.5$ & $2.6 \pm 0.3$ \\
\hline & Range & $58.5-61.0$ & $2.5-3.1$ & $14.6-16.2$ & $2.5-3.3$ & $15.8-17.2$ & $1.9-2.9$ \\
\hline \multirow[t]{4}{*}{ Mihão ( $n=15)$} & Presence & $15 \mathrm{P}$ & $8 \mathrm{IM}, 7 \mathrm{M}$ & $2 \mathrm{~S}, 13 \mathrm{IM}$ & $4 \mathrm{IM}, 11 \mathrm{M}$ & 13 S, 2 IM & $1 \mathrm{IM}, 14 \mathrm{M}$ \\
\hline & $\%$ & 100 & $53.5,46.7$ & $13.3,86.7$ & $26.7,73.3$ & $86.7,13.3$ & $6.7,93.3$ \\
\hline & Mean \pm SD & $59.9 \pm 0.8$ & $2.9 \pm 0.3$ & $15.4 \pm 0.4$ & $2.8 \pm 0.2$ & $16.7 \pm 0.6$ & $2.3 \pm 0.5$ \\
\hline & Range & $57.3-60.5$ & $2.0-3.1$ & $14.8-16.0$ & $2.5-3.0$ & $15.8-18.0$ & $1.9-3.8$ \\
\hline \multirow[t]{4}{*}{ Angueira $(n=15)$} & Presence & $15 \mathrm{P}$ & $5 \mathrm{IM}, 10 \mathrm{M}$ & $1 \mathrm{~S}, 14 \mathrm{IM}$ & $6 \mathrm{IM}, 9 \mathrm{M}$ & 13 S, 2 IM & $15 \mathrm{M}$ \\
\hline & $\%$ & 100 & $33.3,66.7$ & $6.7,93.3$ & $4.0,60.0$ & $86.7,13.3$ & 100 \\
\hline & Mean \pm SD & $59.8 \pm 0.9$ & $2.9 \pm 0.1$ & $15.6 \pm 0.7$ & $2.9 \pm 0.2$ & $16.5 \pm 0.5$ & $2.4 \pm 0.4$ \\
\hline & range & $58.0-61.0$ & $2.8-3.2$ & $14.8-17.7$ & $2.6-3.1$ & $15.8-17.0$ & $1.8-2.9$ \\
\hline \multirow[t]{4}{*}{ Bragança $(n=15)$} & Presence & $15 \mathrm{P}$ & $7 \mathrm{IM}, 8 \mathrm{M}$ & $4 \mathrm{~S}, 11 \mathrm{IM}$ & $3 \mathrm{IM}, 12 \mathrm{M}$ & 14 S, 1 IM & $15 \mathrm{M}$ \\
\hline & $\%$ & 100 & $46.7,53.3$ & $26.7,73.3$ & $20.0,80.0$ & $93.3,1.3$ & 100 \\
\hline & Mean \pm SD & $59.4 \pm 0.9$ & $2.9 \pm 0.2$ & $15.7 \pm 0.6$ & $2.8 \pm 0.1$ & $16.6 \pm 0.5$ & $2.6 \pm 0.2$ \\
\hline & Range & $58.2-61.3$ & $2.7-3.1$ & $15.0-16.9$ & $2.5-3.0$ & $15.9-17.5$ & $2.0-2.9$ \\
\hline \multirow[t]{4}{*}{ Vinhai $(n=15)$} & Presence & $15 \mathrm{P}$ & $5 \mathrm{IM}, 10 \mathrm{M}$ & $8 \mathrm{~S}, 7 \mathrm{IM}$ & $2 \mathrm{IM}, 13 \mathrm{M}$ & 12 S, 3 IM & $15 \mathrm{M}$ \\
\hline & $\%$ & 100 & $33.3,66.7$ & $53.3,46.7$ & $13.3,86.7$ & $80.0,20.0$ & 100 \\
\hline & Mean \pm SD & $59.5 \pm 0.8$ & $2.8 \pm 0.3$ & $15.9 \pm 0.4$ & $2.8 \pm 0.1$ & $16.4 \pm 0.5$ & $2.6 \pm 0.2$ \\
\hline & range & $58.3-61.0$ & $2.1-3.1$ & $15.0-16.7$ & $2.6-3.0$ & $15.3-17.1$ & $2.1-2.9$ \\
\hline \multirow[t]{4}{*}{ Trás-Os-Montes region $(n=75)$} & Presence & $75 \mathrm{P}$ & $33 \mathrm{IM}, 42 \mathrm{M}$ & 17 S, 58 IM & $19 \mathrm{IM}, 56 \mathrm{M}$ & $65 \mathrm{~S}, 10 \mathrm{IM}$ & $1 \mathrm{IM}, 74 \mathrm{M}$ \\
\hline & $\%$ & 100 & $44.0,56.0$ & $22.7,77.3$ & $25.3,74.7$ & $86.7,13.3$ & $1.3,98.7$ \\
\hline & Mean \pm SD & $59.7 \pm 0.8$ & $2.9 \pm 0.2$ & $15.6 \pm 0.6$ & $2.8 \pm 0.2$ & $16.5 \pm 0.5$ & $2.5 \pm 0.4$ \\
\hline & Range & $57.3-61.3$ & $2.0-3.2$ & $14.6-17.7$ & $2.5-3.3$ & $15.3-18.0$ & $1.8-3.8$ \\
\hline
\end{tabular}

P-predominant pollen (>45\%); S-secondary pollen, (16-45\%); IM-important minor pollen, (3-15\%); M-minor pollen, (1-3\%).

a $n=$ sample size.

b Percentage of representation in the studied samples. 
Other pollen grains found in all samples analyzed were: Echium sp. (in $86.7 \%$ and $13.3 \%$ of the total honeys as S and IM pollen respectively) and Castanea sp. (present in $22.7 \%$ and $77.3 \%$ of the total honeys as S and IM pollen respectively). Next Lavandulla sp. and Cistus sp. pollen grains were found as IM and M pollen. Lavandula pollen was IM in $44 \%$ and $\mathrm{M}$ in $56 \%$ of the total honeys from the Trás-Os-Montes region. Cistus found as IM in $25.3 \%$ and as $\mathrm{M}$ in $74.7 \%$, together with Rubus sp. as IM in $1.3 \%$ and as M in $98.7 \%$ of the total honeys, complete the pollen profile of the analyzed organic honeys. Variations in nectar content, together with other factors such as climatic conditions, soil type, beekeeper activities and such, contribute to the existence of different types of honeys (Anklam, 1998). Differences in their composition, also mean differences in the organoleptic and nutritional properties of these honeys. However, to determine the origin, pollen analysis is very efficient for the differentiation of honeys produced in distinctly different geographical and climatic areas. For example, previous work showed that monofloral Erica honey, from the Portuguese Entre-Douro e Minho region, contained Eucalyptus pollen (Feás et al., 2010a), the latter is not found in the organic Erica honeys analyzed in the present work.

In Europe more than 100 botanical species can give unifloral honeys. Most of them are only important at a local level and are thus marketed on a limited scale, but they have been described in the literature (Bogdanov and Persano, 2004). Heather honey is produced in Portugal from Erica sp., while in Spain and France it comes from either Calluna or Erica sp. This honey is characterized by its dark brown color, strong flavor and a slightly salty taste. Consumers in Portugal and Central Europe prefer dark honeys, such as heather honeys, and they are more costly than others and in higher demand from the consumer, which means that they also have a higher commercial value for the producers (Andrade et al., 1999). The heather honey is relatively rarely occurring sort of honey: crystallizes in fine grains and forms gel-like structure of dense fluid. It was stated that heather honeys exhibited nonNewtonian, shear-thinning behavior with tendency to yield stress and they were thixotropic, as well (Witczak et al., 2011).

\subsection{Physico-chemical analysis}

Table 2 shows the results obtained from physico-chemical analysis of the honey samples including: moisture, electrical conductivity, ash, hydroxymethylfurfural (HMF), diastase activity, $\mathrm{pH}$, free acidity, reducing sugars and apparent sucrose.

The maximum amount of water present in honey is the only composition criteria which as a part of the Honey Standard, has to be met for all world trade honeys. In Codex Alimentarius (2001) and EU (2002) the maximum moisture content value of pure floral honey is given as 23\% for heather (Calluna) honeys and not more than $20 \%$ in general. Knowledge of the moisture in honey is useful to improve its conservation and storage since it prevents the growth of molds such as Penicillium and Mucor on its surface. Furthermore, the moisture value is also of great importance because it is considered to be a useful parameter for describing moistness and viscosity of honey. The moisture (\%) varied from 14.5 to 16.3 (mean value $\pm S D=15.6 \pm 0.5 \%$ ). The small variation observed in the water contents of these organic honeys from the Trás-Os-Montes may be due to the similar bee-hive handling practices applied by Portuguese beekeepers. The water content of honey depends on various factors, for example: the harvesting season, the degree of maturity reached in the hive, and environmental factors (Acquarone et al., 2007).

HMF and diastase activity are parameters widely recognized for the evaluation of honey freshness and/or overheating. No sample exceeded the limits established for these variables by international regulations: a minimum value of 8 on Gothe's scale for diastase

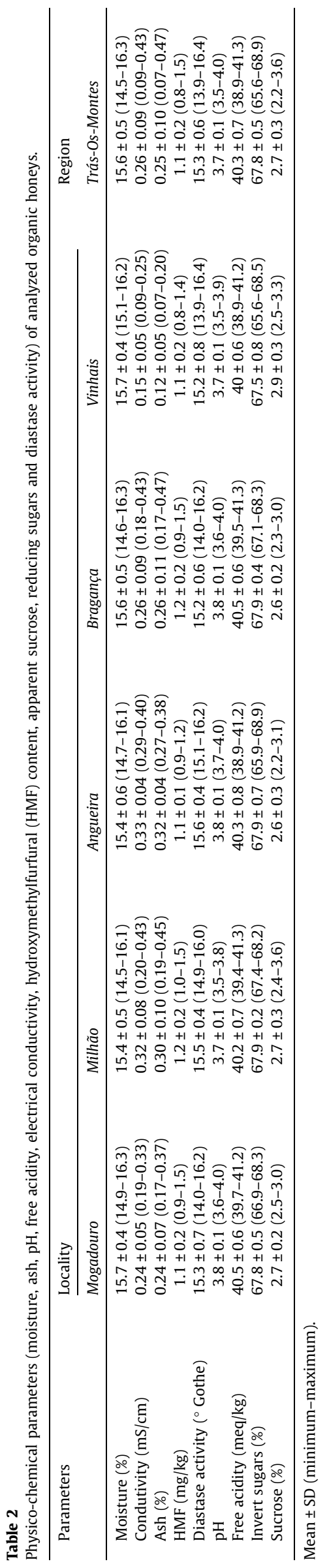


activity, and a maximum HMF content of $40 \mathrm{mg} / \mathrm{kg}$ (Codex Alimentarius, 2001; EU, 2002). The HMF content of the organic honeys analyzed ranged from 0.8 to $1.5 \mathrm{mg} / \mathrm{kg}$ (mean value $\pm \mathrm{SD}=1.1$ $\pm 0.2 \mathrm{mg} / \mathrm{kg}$ ). Values obtained for HMF and diastase activity are typical of unprocessed honey. In honey, these parameters are related to its quality, freshness and heat processing but have not been related to the origin of the samples (Anklam, 1998). A high quality honey is expected to have high diastase activity but a low HMF content. From this point of view most of the samples analyzed are fresh, and thus, coincide with the information provided by the producers. The diastase activity of honey samples is 15.3 (Gothe degrees) (average) with a range of 13.9-16.4 and a standard deviation of 0.6.

The organic honey samples presented a $\mathrm{pH}$ from 3.5 to 4.0 , with an average of 3.7. The low pH of honey inhibits the presence and growth of microorganisms and makes honey compatible with many food products in terms of $\mathrm{pH}$ and acidity. This parameter is of great importance during the extraction and storage of honey as it influences the texture, stability and shelf life of honey (Terrab et al., 2004). Furthermore, the values of $\mathrm{pH}$ in honey help to determine its origin: flower or forest; the latter show higher values. Published reports indicate that the $\mathrm{pH}$ should be between 3.2 and 4.5 (Bogdanov et al., 1997).

Ash and electrical conductivity values depend on the mineral content of the honey: ash gives a direct measure of inorganic residue after carbonization, while electric conductivity measures all ionizable organic and inorganic substances. The honeys considered in this study had ash contents ranging from $0.07 \%$ to $0.47 \%$. Ash values were below $0.60 \%$, as expected for nectar honeys (Codex Alimentarius, 2001; EU, 2002). The electrical conductivity values of the honeys analyzed ranged from 0.09 to $0.43 \mathrm{mS} / \mathrm{cm}$ (mean value $\pm \mathrm{SD}=0.26 \pm 0.09 \mathrm{mS} / \mathrm{cm}$ ). The electrical conductivity of honey may be explained by taking into account the ash and acid content of honey, which reflects the presence of ions and organic acids. The electrical conductivity is a useful parameter in determining botanical origin of honey and differentiating between nectar honey and honeydew. The use of ash determination might be explained by it is importance in the evaluation of contamination with mineral material.

The free acidity of organic honey samples is $40.3 \mathrm{meq} / \mathrm{kg}$ (mean) with a range of 38.9-41.3 and a standard deviation of $0.7 \mathrm{meq} / \mathrm{kg}$. Variation in free acidity among different honeys can be attributed to floral origin or to variation because of the harvest season (Pérez-Arquillué et al., 1995). The free acidity of honey may be explained by taking into account the presence of organic acids in equilibrium with their corresponding lactones, or internal esters, and some inorganic ions, such as phosphate (Finola et al., 2007). All of the samples investigated met the demands set out in the regulations, (Codex Alimentarius, 2001; EU, 2002), which require in general not more than $50 \mathrm{meq} / \mathrm{kg}$ and not more than $80 \mathrm{meq} / \mathrm{kg}$ (baker's honey).

Honey is mainly composed of the monosaccharides glucose and fructose. The reducing sugars (\%) content of the honeys analyzed ranged from $65.6 \%$ to $68.9 \%$ (mean value $\pm \mathrm{SD}=67.8 \pm 0.5$ ) and the mean percentages of apparent sucrose is $2.7 \%$ with a range of 2.2-3.6 and a SD of 0.3 (sucrose content by European Directives must be under $5 \%$ ).

\subsection{Bioactive compounds}

The differences in levels of phenols and flavonoids among regions were assessed through analyses of variance and Duncan's test of means (Table 3). Apart from the region term, the analyses of variance also considered a nested term of sampling locations within a region. This term was in all cases significant, which suggested the presence of differences in phenols and flavonoids levels in honey among the sampling locations within a region. Significant variations across Portuguese localities were also observed. The locality of Bragança produced honeys with the highest level of phenols $(698 \mathrm{mg} / \mathrm{kg}$ ), while the regions of Angueira and Mogadouro produced honeys with the highest concentration of flavonoids ( $537 \mathrm{mg} / \mathrm{kg}$ ). The results of this study were similar to the reported by Ferreira et al. (2009), in dark honeys collected in the Montesinho Natural Park, an area considered as protected.

\subsection{Microbiological analyses}

Honey in spite of its usefulness is known to contain certain microbes. Microorganisms that survive in honey are those that withstand the concentrated sugar, acidity and other antimicrobial characters of honey. In any case this natural reservoir for microbes does not diminish the many important uses that honey is known for. Microbial counts in organic honey samples are presented in Table 4 . The levels of quantitation for the commercial quality parameters (aerobic mesophiles and molds and yeasts) in the organic

Table 3

Total phenolics and flavonoids (mean \pm SD) obtained for the organic honey samples.

\begin{tabular}{|c|c|c|c|c|c|c|}
\hline & \multicolumn{5}{|l|}{ Locality $^{\mathrm{A}}$} & \multirow{2}{*}{$\begin{array}{l}\text { Region } \\
\text { Trás-Os-Montes }\end{array}$} \\
\hline & Mogadouro & Milhão & Angueira & Bragança & Vinhais & \\
\hline Phenols (mg/kg) & $678.4 \pm 26.4 \mathrm{~b}$ & $683.6 \pm 22.8 \mathrm{~b}$ & $684.8 \pm 30.5 b$ & $698.1 \pm 20.4 \mathrm{a}$ & $679.5 \pm 37.5 b$ & $684.9 \pm 28.3$ \\
\hline Flavonoids $(\mathrm{mg} / \mathrm{kg})$ & $537.0 \pm 54.7 \mathrm{a}$ & $494.4 \pm 41.4 \mathrm{c}$ & $563.3 \pm 66.2 \mathrm{a}$ & $506.2 \pm 65.5 \mathrm{bc}$ & $516.4 \pm 71.7 \mathrm{ab}$ & $518.1 \pm 61.6$ \\
\hline
\end{tabular}

${ }^{\text {A }}$ Horizontally, localities with a different letter denote statistical difference in means.

Table 4

Microbial analyses of organic honey samples.

\begin{tabular}{|c|c|c|c|c|c|c|}
\hline \multirow{2}{*}{$\begin{array}{l}\text { Microbiological } \\
\text { determination }\end{array}$} & \multicolumn{5}{|l|}{ Locality } & \multirow{2}{*}{$\begin{array}{l}\text { Region } \\
\text { Trás-Os-Montes }\end{array}$} \\
\hline & Mogadouro & Milhão & Angueira & Bragança & Vinhais & \\
\hline Molds and yeast ${ }^{\mathrm{a}}$ & $5.5 \pm 1.8$ & $5.5 \pm 2.0$ & $5.5 \pm 2.3$ & $5.7 \pm 1.0$ & $5.2 \pm 2.0$ & $5.5 \pm 1.8$ \\
\hline Aerobic mesophiles ${ }^{a}$ & $1.9 \times 10^{2} \pm 4.3 \times 10^{1}$ & $2.1 \times 10^{2} \pm 3.9 \times 10^{1}$ & $1.1 \times 10^{2} \pm 7.4 \times 10^{1}$ & $7.2 \times 10^{1} \pm 3.0 \times 10^{1}$ & $1.4 \times 10^{2} \pm 75.5 \times 10^{1}$ & $1.3 \times 10^{2} \pm 7.5 \times 10^{1}$ \\
\hline Fecal coliforms ${ }^{b}$ & $<1$ & $<1$ & $<1$ & $<1$ & $<1$ & $<1$ \\
\hline $\begin{array}{l}\text { Sulphite-reducing } \\
\text { clostridia }^{c}\end{array}$ & Absent & Absent & Absent & Absent & Absent & Absent \\
\hline Salmonella ${ }^{\mathrm{d}}$ & Absent & Absent & Absent & Absent & Absent & Absent \\
\hline
\end{tabular}

a Colony-forming units per gram of honey (cfu/g).

b Total coliformes were enumerated by the Most Probable Number (MPN).

c (in $0.01 \mathrm{~g}$ ).

d (in $25 \mathrm{~g}$ ). 
honey samples analyzed are generally lower than those reported by other authors. Yeast and molds were detected in low counts, with means values obtained of $5.5 \mathrm{cfu} / \mathrm{g}$. The presence of fungi in honey is linked to contact with the intestinal contents of bees, bee hive and grass. In fact, the primary sources of sugar tolerant yeast are flowers and soil. From the microbiological point of view, these low values of molds and yeasts are most probably related to the environmental conditions, and are indicative of an appropriate management of apiaries. The total aerobic mesophiles counts in the samples ranged from $7.2 \times 10^{1} \mathrm{cfu} / \mathrm{g}$, found in organic honeys sampled from Vinhais, to $2.1 \times 10^{2} \mathrm{cfu} / \mathrm{g}$ from Milhão. The mean value of total aerobic mesophiles obtained from organic honeys from the Trás-Os-Montes was established in $1.3 \times 10^{2} \mathrm{cfu} / \mathrm{g} \pm 7.5 \times$ $10^{1} \mathrm{cfu} / \mathrm{g}$, Iurlina and Fritz (2005) found higher levels of contamination for both aerobic mesophiles (average $244 \mathrm{cfu} / \mathrm{g}$ ) and mold and yeasts (average $34 \mathrm{cfu} / \mathrm{g}$ ) counts. In respect to sanitary quality (fecal coliforms) and safety (sulphite-reducing clostridia and Salmonella), all our samples were negative. Having reviewed the scientific literature, Clostridiums appears to be the main microorganism in honey of concern to human health. Its presence in honey is especially dangerous for babies under one year old, since they do not have a fully developed immune system, and honey is the only dietary vehicle so far definitively linked to infant botulism. Honey samples collected at retail level were found to be contaminated with Clostridium botulinum spores in the USA (10\% of the analyzed samples), Japan (8.5\%), Brazil (7.5\%) and Italy (6.5\%); with contamination levels between 5 and 80 spores per g of product (Nakano and Sakaguchi, 1991). EU legislation lacks specifications concerning microbiological contamination and hygiene of the product. In fact, numerous studies have been reported on the physicochemical parameters of honeys from all over the world, but microbiological contamination studies are few and are essentially devoted to $C$. botulinum. It is recommended that effective and targeted information regarding risks of infant botulism from the consumption of honey should be provided, e.g. via leaflets, labeling and advice to health-care professionals.

To investigate the relative importance of the chemical properties on the levels of mesophiles and molds present in honey, a general linear model was fitted independently for the mesophiles and molds as dependent variables with moisture, ash, acidity, $\mathrm{HMF}, \mathrm{pH}$, sucrose, diastase, inverted sugars, phenols and flavonoids as independent variables. The $F$-values (or $p$-values) of each covariate was ranked accordingly, for both the mesophiles and molds. It was found that the most important variables greatly associated to the levels of mesophiles and molds in honey were in this order the levels of moisture, ash (related to solids), acidity and HMF $(p<0.001)$ (Table 5). The levels of flavonoids had a stronger impact on both mesophiles $(p=0.0004)$ and molds $(p=0.0138)$ than the sucrose concentration ( $p=0.001$ and 0.0278 ; respectively). The amount of diastase in honey was not as associated to the numbers of molds $(p=0.194)$ as occurred with the numbers of mesophiles

\section{Table 5}

Chemical characteristics of organic honey as sources of variability in mesophiles and molds numbers ranked according to $p$-values. Ranks are shown in brackets.

\begin{tabular}{lll}
\hline $\begin{array}{l}\text { Chemical composition/ } \\
\text { property }\end{array}$ & $\begin{array}{l}\text { Mesophiles } \\
\left(R^{2}=0.861\right)\end{array}$ & $\begin{array}{l}\text { Molds } \\
\left(R^{2}=0.686\right)\end{array}$ \\
\hline Moisture & $<.0001(1)$ & $<.0001(1)$ \\
Ash & $<.0001(2)$ & $<.0001(2)$ \\
Acidity & $<.0001(3)$ & $0.0002(3)$ \\
HMF & $<.0001(4)$ & $0.0017(4)$ \\
Flavonoids & $0.0004(5)$ & $0.0138(6)$ \\
pH & $0.0011(7)$ & $0.0087(5)$ \\
Sucrose & $0.0010(6)$ & $0.0278(7)$ \\
Diastase & $0.0017(8)$ & $0.1940(9)$ \\
Inverted sugar & $0.7905(10)$ & $0.0789(8)$ \\
Phenols & $0.1160(9)$ & $0.6181(10)$ \\
\hline
\end{tabular}

$(p=0.002)$. Finally, the levels of inverted sugar and total phenols did not have a significant association with the levels of both mesophiles and molds. The chemical properties considered explained $86.1 \%$ of the variability in mesophiles levels while the same properties explained $68.6 \%$ of the variability in the numbers of molds (Table 5).

\section{Conclusion}

Organic honeys are produced using strict ecological and natural principles which are meant to enhance the good quality of the honey harvested. Correlating the palynological, physico-chemical and microbiological results is necessary in order to check the authenticity, quality and the sanitation of honey. However, this constitutes only practical proof in insuring food safety. Organic honey samples harvested from beekeepers in the Trás-Os-Montes (Portugal) can be classified as monofloral heather (Erica sp.) and all of the values obtained for the physico-chemical parameters were within the limits imposed by the present legislation. The highest amounts of phenols were detected in the samples from Bragança, related with the abundance of Ericaceae plants in this area. However, the flavonoids were higher in Angueira and Mogadouro. From the economical standpoint, the assessment of a monofloral origin may increase the commercial value of these honeys. Monofloral honeys, originating predominantly from a single botanical source, are in higher demand from the consumer, which means that they also have a higher commercial value for the producers. The results reported in this study should be introduced in the organic honey label, and may help beekeepers, industry, researchers and consumers better understand honey properties.

\section{Conflict of Interest}

The authors declare that there are no conflicts of interest.

\section{Acknowledgements}

We would like to thank the Portuguese beekeepers who kindly supplied us with the honeys for this study. Xesús Feás would also like to thank the Xunta de Galicia (Isidro Parga Pondal Program for young researchers, Grant No.: IPP-020). Our thanks to JoDee Anderson for the linguistic support she provided as well.

\section{References}

Acquarone, C., Buera, C., Elizalde, B., 2007. Pattern of pH and electrical conductivity upon honey dilution as a complementary tool for discriminating geographical origin of honeys. Food Chemistry 101, 695-703.

Akbulut, M., Özcan, M.M., Çoklar, H., 2009. Evaluation of antioxidant activity, phenolic, mineral contents and some physicochemical properties of several pine honeys collected from Western Anatolia. International Journal of Food Sciences and Nutrition 60, 577-589.

Allsopp, M.H., de Lange, W.J., Veldtman, R., 2008. Valuing insect pollination services with cost of replacement. PLoS ONE 3, e3128.

Andrade, P.B., Amaral, M.T., Isabel, P., Carvalho, J.C.M.F., Reabra, R.M., Proença da Cunha, A., 1999. Physicochemical attributes and pollen spectrum of Portuguese heather honeys. Food Chemistry 66, 503-510.

Anklam, E., 1998. A review of the analytical methods to determine the geographical and botanical origin of honey. Food Chemistry 63, 549-562.

Araújo, M.B., 1999. Distribution patterns of biodiversity and the design of a representative reserve network in Portugal. Diversity and Distribution 5, 151-163.

Azeredo, L.C., Azeredo, M.A.A., Sousa, S.R., Dutra, V.M.L., 2003. Protein contents and physicochemical properties in honeys sample from Apis Mellifera of different floral origins. Food Chemistry 80, 249-254.

Bardy, J., Slevin, N.J., Mais, K.L., Molassiotis, A., 2008. A systematic review of honey uses and its potential value within oncology care. Journal of Clinical Nursing 17, 2604-2623.

Bogdanov, S., Persano, L., 2004. Physico-chemical methods for the characterisation of unifloral honeys: a review. Apidologie 35, S4-S17. 
Bogdanov, S., Martin, P., Lüllmann, C., Borneck, R., Flamini, C., Morlot, M., et al., 1997. Harmonised methods of the European Honey Commission. Apidologie 28 $1-59$.

Codex Alimentarius, 2001. Revised Codex Standard for Honey, Codex STAN 12-1981, Rev. 1 (1987), Rev. 2.

Cuthbertson, A.G.S., Brown, M.A., 2009. Issues affecting British honey bee biodiversity and the need for conservation of this important ecological component. International Journal of Environmental Science and Technology 6, 695-699.

Du Toit, I.J., Grobler, S.R., Kotze, V.W.T.J., Basson, N.J., 1995. Fluoride, calcium and phosphorus levels in bee honey and water. South African Journal of Science 91, 391-392.

EU, 1992. Council Directive 92/43/EEC on the conservation of natural habitats and of wild fauna and flora. Official Journal of the European Communities L 206, 7-50.

EU, 2002. Council Directive 2001/110/CE concerning honey. Official Journal of the European Communities L10, 47-52.

EU, 2006. Council Regulation 509/2006 on agricultural products and foodstuffs as traditional specialities guaranteed. Official Journal of the European Communities, L93, 1-6. The full list of products can be found at: <http:// ec.europa.eu/agriculture/foodqual/quali1_en.htm>.

EU, 2007. Council Directive $834 / 2007$ on organic production and labelling of organic products. Official Journal of the European Communities L 189, $1-23$.

Feás, X., Estevinho, L.M., 2011. A survey of the in vitro antifungal activity of heather (Erica sp.) organic honey. Journal of Medicinal Food 14, 1-5.

Feás, X., Pires, J., Estevinho, M.L., Iglesias, A., Pinto de Araujo, J.P., 2010a. Palynological and physicochemical data characterisation of honeys produced in the Entre-Douro e Minho region of Portugal. International Journal of Food Science and Technology 45, 1255-1262.

Feás, X., Pires, J., Iglesias, A., Estevinho, M.L., 2010b. Characterization of artisanal honey produced on the Northwest of Portugal by melissopalynological and physico-chemical data. Food and Chemical Toxicology 48, 3462-3470.

Ferreira, I.C.F.R., Aires, E., Barreira, J.C.M., Estevinho, L.M., 2009. Antioxidant activity of Portuguese honey samples: different contributions of the entire honey and phenolic extract. Food Chemistry 114, 1433-1438.

Finola, M.S., Lasagno, M.C., Marioli, J.M., 2007. Microbiological and chemical characterization of honeys from central Argentina. Food Chemistry 100, 1649-1653.

Gomes, S., Dias, L., Moreira, L., Rodrigues, P., Estevinho, L., 2010. Physicochemical, microbiological and antimicrobial properties of commercial honeys from Portugal. Food Chemical and Toxicology 48, 544-548.
ISO 21527-2:2008. Microbiology of Food and Animal Feeding Stuffs - Horizontal Method for the Enumeration of Yeasts and Moulds - Part 2: Colony Count Technique in Products with Water Activity less than or equal to 0.95 . International Standards Organization, Switzerland.

ISO 6579:2002(E). Microbiology of Food and Animal Feeding Stuffs - Horizonta Method for the Detection of Salmonella spp. International StandardsOrganization, Switzerland.

Iurlina, M.O., Fritz, R., 2005. Characterization of microorganisms in Argentinean honeys from different sources. International Journal of Food Microbiology 105 , 297-304.

Louveaux, J., Maurizio, A., Vorwohl, G., 1970. Methods of melissopalynology. Bee World 51, 125-131.

Magkos, F., Arvaniti, F., Zampelas, A., 2003. Organic food: nutritious food or food for thought? A review of the evidence. International Journal of Food Sciences and Nutrition 54, 357-371.

Molan, P.C., 2001. Potential of honey in the treatment of wounds and burns. American Journal of Clinical Dermatology 2, 13-19.

Moreira, L., Dias, L.G., Pereira, J.A., Estevinho, L.M., 2008. Antioxidant properties, total phenols and pollen analysis of propolis samples from Portugal. Food and Chemical Toxicology 46, 3482-3485.

Nakano, H., Sakaguchi, A., 1991. An unusual heavy contamination of honey products by Clostridium botulinum type $\mathrm{F}$ and Bacillus alvei. FEMS Microbiology Letters 63, 171-177.

Oldroyd, B.P., 2007. What's killing American honey bees? PLoS Biology 5, 1195 1199.

Pérez-Arquillué, C., Conchello, P., Arin 0, A., Juan, T., Herrera, A., 1995 Physicochemical attributes and pollen spectrum of some unifloral Spanish honeys. Food Chemistry 54, 167-172.

Pires, J., Estevinho, M.L., Feás, X., Cantalapiedra, J., Iglesias, A., 2009. Pollen spectrum and physico-chemical attributes of heather (Erica sp.) honeys of north Portugal. Journal of the Science of Food and Agriculture 89, 1862-1870.

Rial-Otero, R., Gaspar, E.M., Moura, I., Capelo, J.L., 2007. Chromatographic-based methods for pesticide determination in honey: an overview. Talanta 71, 503-514.

Terrab, A., Recamales, A.F., Hernanz, D., Heredia, F.J., 2004. Characterisation of Spanish thyme honeys by their physicochemical characteristics and mineral contents. Food Chemistry 88, 537-542.

Theunissen, F., Grobler, S., Gedalia, I., 2001. The antifungal action of three South African honeys on Candida albicans. Apidologie 32, 371-379.

Tucak, Z., Periskić, M., Beslo, D., Tucak, I., 2004. Influence of the beehive type on the quality of honey. Collegium Antropologicum 28, 463-467.

Witczak, M., Juszczak, L., Gałkowska, D., 2011. Non-Newtonian behaviour of heather honey. Journal of Food Engineering 104, 532-537. 